\title{
EL EMPLEO DE DIAGNÓSTICOS MATRICIALES EN LA PLANIFICACIÓN ESTRATÉGICA DE ESPACIOS TURISTICOS DE INTERIOR: UNA PROPUESTA METODOLÓGICAAPLICADA SOBRE EL INTERIOR DE ALICANTE ${ }^{1}$
}

\author{
Daniel Díez Santo \\ Instituto Universitario de Investigaciones Turísticas. Universidad de Alicante \\ daniel.diez@ua.es
}

\section{RESUMEN}

La creación de matrices desempeña una función determinante en los procesos de planificación estratégica, ya sea a través del archiconocido diagnóstico DAFO, como por medio de otras matrices más específicas. En este sentido, el artículo propone la aplicación paralela de cinco matrices específicas con el fin de optimizar y priorizar la definición de objetivos y el diseño de programas de actuación en espacios turísticos de interior.

En concreto, la propuesta metodológica está compuesta por la matriz potencial de los recursos turísticos-interés de la demanda, la matriz importancia actual de los segmentos de demanda-expectativas de crecimiento futuro, la matriz atractivo de mercado-posición competitiva, la matriz importancia de disfunciones-facilidad de resolución y la matriz implantación de actividades turísticas-generación de impactos medioambientales.

Palabras clave: metodología, diagnóstico matricial, planificación estratégica, turismo de interior.

Fecha de recepción: febrero 2011.

Fecha de aceptación: julio 2012.

1 La propuesta metodológica presentada en este artículo forma parte de la Tesis Doctoral La planificación estratégica de los espacios turísticos interiores: una propuesta metodológica aplicada en el interior de Alicante que fue defendida en 2010 dentro del programa de doctorado Planificación y gestión sostenible de destinos turísticos del Instituto Universitario de Investigaciones Turísticas de la Universidad de Alicante. 


\section{ABSTRACT}

The creation of matrices plays a determining role in strategic planning processes, either through the very well-known SWOT diagnosis or by means of other more specific matrices. In this respect, the article suggests the parallel application of five specific matrices with the aim of optimising and prioritising the definition of goals and the design of action programmes for inland tourism spaces.

More precisely, the methodological proposal comprises the potential tourism resourcesinterest of the demand matrix, the current importance of demand segments-future growth expectations matrix, the market attractiveness-competitive position matrix, the importance of dysfunctions-resolution easiness matrix, and the implementation of tourism activitiesgeneration of environmental impacts matrix.

Key words: methodology, matrix diagnosis, strategic planning, inland tourism.

\section{LA PLANIFICACIÓN TURÍSTICA DESDE LA PERSPECTIVA TERRITORIAL: UNA APROXIMA- CIÓN ORIENTADA A LOS ESPACIOS TURÍSTICOS DE INTERIOR}

La planificación turística no es método único y uniforme que sea aplicable de igual modo en todos los espacios. Según las características de cada territorio el proceso, los métodos y sobre todo, los objetivos de la planificación turística pueden variar notablemente. En este sentido han sido numerosos los autores que han ido creando metodologías sobre planificación turística: Pearce (1988), Boullon (1989), Inskeep (1991), Pujol (1991), Smith (1991), Mcintyre (1993), Gunn (1994), Esteban (1996), Horner y Swarbrooke (1996), Ivars (2003), entre otros.

Murphy (1985) introduce en el concepto de planificación turística la variable social, económica y ambiental al indicar que «la planificación implica anticipar los cambios en un sistema determinado, con el objeto de promover un desarrollo ordenado, maximizando los beneficios sociales, económicos y ambientales en una secuencia ordenada de operaciones, encaminada a la consecución de uno o varios objetivos». Por su parte, Genz (1987) ${ }^{2}$ identifica cuatro tradiciones fundamentales en la planificación turística:

- Planteamiento boostering: El turismo es una actividad totalmente beneficiosa y el alcance de sus operaciones debe ser maximizado.

- Planteamiento económico: El turismo es considerado un valioso factor para el desarrollo económico y su mayor utilidad es la de generar renta y empleo para las regiones.

- Planteamiento físico-espacial: El turismo debe desarrollarse teniendo en cuenta la minimización de impactos negativos sobre el medio ambiente.

- Planteamiento comunitario: El turismo es conceptualizado como una fuerza económica y política que tiene su mejor desarrollo a través del control local.

2 Citado por Ivars (2003). 
En la planificación de espacios turísticos de interior debe primar el planteamiento comunitario, sobre todo en las zonas más rurales donde el desarrollo endógeno ha de ser el pilar fundamental de cualquier proceso de desarrollo socioeconómico ${ }^{3}$. No obstante, la diversidad territorial de los espacios interiores obliga también a tener en consideración el planteamiento físico-espacial, sobre todo en espacios naturales protegidos o de interés paisajístico y medioambiental, y el planteamiento económico sobre todo en los principales núcleos urbanos. La singularidad de un ámbito espacial en el que se produce una gran simbiosis entre naturaleza y sociedad local sirve de argumento para tratar de armonizar intereses entre las vertientes ambiental, turística y social, manteniendo como principios fundamentales el uso sostenible de los recursos, la revitalización de las economías locales, la integración de la población en los procesos y en un desarrollo equilibrado y controlado que impida la masificación y los impactos negativos (Vera, et. Al., 2011).

Según la OMT (1999), la planificación turística de un destino ha de abordarse como un sistema en el que se interrelacionan factores de la demanda (mercados turísticos actuales y potenciales) y de la oferta (atracciones, transportes, instalaciones, servicios y promoción). Sin embargo, debido a las interrelaciones que existen entre los distintos elementos es importante que la planificación del turismo tenga como objetivo un desarrollo lo más integrado posible de todas las partes del sistema, de forma que todas ellas sean debidamente consideradas a lo largo del proceso de planificación.

Para Inskeep (1991) la planificación turística es un proceso continuo y flexible, en el marco del cual deben enunciarse recomendaciones de políticas y planes, pero que deben tener la suficiente flexibilidad como para permitir la adaptación a las circunstancias cambiantes de los destinos. Mientras que para Solsona (2009) la planificación turística es un proceso a través del cual se ordena y racionaliza en un destino turístico, o potencialmente turístico, los recursos, atractivos, infraestructuras, equipamientos y servicios y, en general, todos los elementos que integran la oferta, adecuándolos a las necesidades de la demanda y las tendencias del mercado.

En apretada síntesis, la planificación turística se puede considerar como un proceso organizado y sistemático para la selección de unos objetivos y los mejores medios para alcanzarlos teniendo siempre en cuenta un elevado componente de previsión ${ }^{4}$.

Según Gunn (1994) y Solsona (2009), los principales fines que persigue la planificación turística son los siguientes:

- Establecimiento de los objetivos de desarrollo turístico y las políticas para conseguirlos. Objetivos que no se circunscriben a los meramente turísticos, sino que engloban otros de diversa naturaleza: económicos, ambientales, sociales, culturales, etc.

3 El desarrollo turístico en el espacio rural y natural debe ser de carácter extensivo, frente a los desarrollos intensivos del espacio urbano o litoral, de otro modo no podría conservarse la esencia del territorio, que es lo que da la razón de ser al turismo rural. Ello requiere de un esmerado trabajo de planificación debido a que los recursos que se gestionan son frágiles y vulnerables, porque su conservación es la garantía de permanencia a medio y largo plazo y porque el buen estado de los recursos naturales es el único y más preciado patrimonio con que cuentan muchas poblaciones rurales (Bernabé y Viñals, 1999).

4 El pasado y el presente son puntos de referencia para transformar la realidad de acuerdo con unos límites preestablecidos (Dias, 2003). Un plan sería el equivalente al «Antiazar» (Bote, 1990). 
- Garantizar la conservación actual y futura de los recursos turísticos, al tiempo que se asegura su uso en el presente. La sostenibilidad del desarrollo que va a producirse y la protección del entorno medioambiental como recurso fundamental de la actividad turística en el espacio rural, así como la limitación de las capacidades de carga.

- Integrar los objetivos del turismo con las restantes políticas de desarrollo socioeconómico, favoreciendo las relaciones del turismo con otros sectores. Para ello resulta clave la implicación de los agentes locales y las instituciones públicas.

- Ofrecer una información rigurosa y útil a la toma de decisiones públicas y privadas.

- Hacer posible la coordinación de la amalgama de elementos que intervienen en el sector turístico.

- Optimizar los beneficios económicos, ambientales y sociales del turismo, favoreciendo una buena distribución social y minimizando los posibles problemas derivados del turismo.

- Establecer las directrices básicas para la elaboración de planes de detalle que consideren la escala del territorio, favoreciendo su coordinación y reforzando unos con otros.

- Facilitar el marco institucional y organizativo para el desarrollo de la planificación y la gestión turística.

En concreto, atendiendo a singularidad específica de los espacios rurales que se caracterizan por organizarse a partir de microdestinos, pequeñas empresas y productos poco dimensionados (Pulido, 2005), un primer inconveniente que aparece a la hora de planificar estos espacios es su difícil delimitación. La progresiva convergencia entre espacios rurales y urbanos en cuanto a estilos de vida, intercambio funcional, dependencia, etc., dificultan su identificación. En este sentido, pueden distinguirse áreas rurales de influencia urbana, próximas o con elevada accesibilidad respecto a las áreas metropolitanas, con problemas asociados de competencias por los usos del suelo. Pero también, transformación paisajística e impacto ambiental, áreas rurales en decadencia afectadas por el ciclo del declive rural y áreas rurales de elevada fragilidad donde a las circunstancias propias del declive rural se suman a un medio físico de difícil accesibilidad (Antón y González, 2005).

Por todo ello, la planificación resulta fundamental para corregir o prever conflictos, siempre que se oriente a través de unos principios básicos: no planificar sin los recursos o atractivos suficientes; diseñar un plan global que permita dar resultados a largo plazo; comenzar con objetivos definidos (aumento de la renta, conservación de la población, etc.); buscar ámbitos de carácter comarcal; contar con la coordinación de estrategias entre la Administración Pública y la iniciativa privada en la que el capital social cobra un protagonismo creciente; y, sobre todo, no olvidar que los turistas cada vez están más informados, demandan experiencias de calidad, de ahí que la conservación del patrimonio y del entorno natural sean inseparables de la actividad (Orduna, 2002).

\section{LA PLANIFICACIÓN ESTRATÉGICA DEL TURISMO: UN ENFOQUE DESDE LA DIMENSIÓN DE LA COMPETITIVIDAD TERRITORIAL}

La idea central que gira en torno a la planificación estratégica es prever situaciones futuras a partir de diferentes escenarios posibles (continuidad o cambio) y tratar de responder a las nuevas situaciones desde un punto de vista organizativo. 
Los principales factores diferenciales de la planificación estratégica del turismo son que anticipa el futuro a través de la definición de un amplio horizonte temporal, asegura la reconversión de las ciudades, permite establecer una cultura local, orienta los objetivos a partir de los recursos existentes, afecta a todo tipo de actividades, incluye fórmulas de gestión participativas, se centra en objetivos críticos, diagnostica oportunidades, peligros, debilidades y potencialidades, da prioridad al análisis del entorno competitivo (el espacio como producto), busca objetividad en relación con puntos fuertes y débiles, incide en los puntos fuertes, fomenta la cooperación público-privada a través de la creación de canales de coordinación, sitúa los problemas locales de manera comparada, ayuda a deshacer malentendidos sobre la dinámica local, enfoca la energía hacia aspectos prioritarios, proporciona interés personal, ayuda a crear productos estrella, se enfoca a la acción, revaloriza la planificación como proceso continuo y se integra en la gestión (Antón y González, 2005).

La planificación estratégica, a diferencia de la planificación de carácter normativo, tiene una serie de ejes a los que dirige las actuaciones: define un modelo territorial global, concentra de forma selectiva los esfuerzos públicos, realiza actuaciones impulsoras y de demostración y busca un clima participativo e interdisciplinal (Antón y González, 2005). Asimismo, la difusión de la planificación estratégica en turismo ha permitido que se den cambios importantes en los destinos, ya que ha generalizado los conceptos de calidad, sostenibilidad, coordinación interadministrativa, implicación del sector empresarial o la mejora e incorporación de nuevos productos turísticos (Rivas, 2006).

Los planes estratégicos tratan de responder a las incertidumbres turísticas de los mercados, adecuando las ofertas de productos turísticos de la propia región, comarca o municipio, a las exigencias dinámicas de la demanda. Sin embargo, el aspecto fundamental de la planificación estratégica en turismo es el de la firme convicción de la necesidad de abordar el proceso desde una óptica de involucración del mayor número posible de agentes sociales y económicos. Un plan estratégico es, en esencia, un ejercicio de participación y consenso de todas las fuerzas económicas y sociales con capacidad de decisión e inversión en la mejora del ciclo de vida del producto ${ }^{5}$ y la competitividad del territorio turístico (Vera, et. al., 1997).

La planificación que define el modelo territorial-turístico tiene que concebir el futuro deseado y los medios para alcanzarlo. Siempre hay que mantener la visión estratégica que identifica el modelo futuro deseado y aceptado socialmente. Según Kotler et al. (1997), los problemas empiezan para aquellos que piensan que el futuro será como el presente, «los recursos, bienes y ventajas de los que ciertos lugares disfrutan en la actualidad puede que no proporcionen las mismas oportunidades dentro de una década».

5 Butler (1980) estableció un modelo de ciclo de vida de los productos basado en una secuencia evolutiva en cuatro etapas básicas: introducción (exploración e implicación), desarrollo, madurez y estancamiento (declive o renovación). A través de este modelo se puede llevar a cabo un análisis comparativo/competitivo del destino, reconociendo y estudiando los distintos estadios por los que atraviesa, ya que al tratarse de un estudio longitudinal, permite analizar la evolución del mercado sentando las bases para planificar su futuro desarrollo (Choy, 1992). 


\section{EL EMPLEO DE DIAGNÓSTICOS MATRICIALES EN LA PLANIFICACIÓN ESTRATÉGICA DE ESPACIOS TURÍSTICOS DE INTERIOR}

Las matrices representan una técnica extremadamente útil para organizar y estructurar la información en los análisis y diagnósticos científicos. La matriz más conocida y más comúnmente empleada en estudios sociales, económicos y geográficos es la matriz DAFO. Esta técnica ayuda a identificar y organizar aquellos factores que inciden directamente sobre la competitividad de una empresa, actividad económica o territorio.

El DAFO, también denominado SWOT (según sus siglas en inglés) o FODA, es una herramienta de diagnosis enormemente eficiente, tanto que se constituye como parte, prácticamente ineludible, de cualquier plan estratégico, y por supuesto, también en los abundantes planes estratégicos de turismo que en las últimas décadas han sido redactados (Solsona, 2009). El diagnóstico DAFO se descompone en cuatro factores básicos:

- Debilidades (factor negativo, interno y actual): Deficiencias y disfunciones que presenta el destino, sus recursos y las empresas turísticas implantadas.

- Amenazas: (factor negativo, externo y futurible): Riesgos que presenta el entorno que pueden afectar al destino en función de sus vulnerabilidades específicas.

- Fortalezas (factor positivo, interno y actual): Capacidades especiales, habilidades de los habitantes, recursos del destino turístico, etc.

- Oportunidades (factor positivo, externo y futurible): Factores explotables del entorno.

Posteriormente, este diagnóstico debe servir para diseñar estrategias encaminadas a detener y minimizar las debilidades, defender y contrarrestar las amenazas, explotar las fortalezas y aprovechar las oportunidades.

El diagnóstico DAFO a parte de recopilar y organizar la información obtenida en el análisis del estado de la situación, puede servir también como instrumento eficaz para la recogida de más información si se elabora de un modo plural. Es decir, el diagnóstico DAFO se puede realizar durante dinámicas de grupo (mesas de trabajo) en las que participen diferentes colectivos de agentes implicados en el turismo. En primer lugar, el proceso puede arrancar con una lluvia de ideas individual, que después pueden generar temas de debate en los que se ubiquen correcta y preferencialmente cada situación dentro de uno de los cuatro factores del diagnóstico DAFO.

Otra técnica cada vez más empleada en la realización de diagnósticos estratégicos es la creación de matrices que ponen en relación varios factores para priorizar actuaciones o inversiones en busca de los mayores niveles de efectividad. En concreto, para la planificación de espacios turísticos interiores se propone la elaboración de cinco matrices básicas: matriz potencial de los recursos turísticos-interés de la demanda; matriz importancia actual de los segmentos de demanda-expectativas de crecimiento futuro; matriz atractivo de mercadoposición competitiva; matriz importancia de disfunciones-facilidad de resolución; y matriz implantación de actividades turísticas-generación de impactos medioambientales. 


\subsection{Matriz potencial de los recursos turísticos-interés de la demanda ${ }^{6}$}

La creación de esta matriz responde a la necesidad de identificar los atractivos turísticos de un espacio de interior que presentan una mayor potencialidad y que suscitan un mayor interés para la demanda. La combinación de ambos factores sirve para priorizar sobre que recursos se debe actuar preferentemente para lograr unos mayores niveles de satisfacción en la demanda y en definitiva, lograr un mayor aprovechamiento de las inversiones públicas.

La ubicación de cada recurso u atractivo en la matriz se realiza de forma cualitativa (potencial de los recursos) y cuantitativa (interés de la demanda) teniendo en cuenta los siguientes criterios que aparecen en la tabla adjunta.

\begin{tabular}{|l|ll|}
\hline \multicolumn{1}{|c|}{ Potencial de los recursos } & \multicolumn{1}{c|}{ Interés de la demanda } \\
\hline - & Singularidad del recurso. & - Valoración demanda alta $(>100 \%)$. \\
- Adaptación del recurso al consumo turístico. & - & Valoración de la demanda media $(50-100 \%)$. \\
- Rehabilitación e interpretación del recurso. & - $\quad$ Valoración de la demanda baja $(10-50 \%)$. \\
\hline
\end{tabular}

Fuente: Elaboración propia.

En este caso, la distribución de los recursos en la matriz da lugar a tres posibles situaciones: recursos de prioridad 1 en los que las actuaciones y las inversiones deben fomentar al máximo la explotación turística de este tipo de recursos; recursos de prioridad 2 en los que las actuaciones y las inversiones deben tratar de mantener el interés de la demanda por este tipo de recursos; y finalmente, recursos de prioridad 3 sobre los que se desaconsejan fuertes inversiones para su puesta en valor.

\subsection{Matriz importancia actual de los segmentos de demanda-expectativas de crecimiento futuro ${ }^{7}$}

La creación de esta matriz responde a la necesidad de identificar que segmentos de mercado son más importantes para el actual turismo de interior y cuales evidencian un mayor potencial de crecimiento futuro. La combinación de ambos factores servirá para priorizar actuaciones encaminadas hacia la captación de los segmentos de mayor interés para el espacio a planificar.

La población difiere considerablemente necesidades, deseos, demanda, hábitos, gustos, actitudes, capacidad adquisitiva, etc. Por ello, a la hora de definir un producto, de establecer su precio, de determinar los canales de distribución, de elaborar la estrategia de comunicación se debe segmentar el mercado en aras de ser más eficientes (reducción de costes) y efectivos (impactar más y mejor al mercado potencial) (Gómez García, 2009).

En la matriz se consideran cuatro criterios básicos para segmentación de mercados: segmentación por edad (jóvenes, mediana edad, tercera edad); segmentación por nivel de estudios (primarios, secundarios, superiores), segmentación por tipo de acompañantes (pareja,

\footnotetext{
6 Matriz creada por el autor (aportación metodológica).
}

7 Matriz creada por el autor (aportación metodológica). 
familia, grupo amigos, solo); y segmentación por origen (turismo de proximidad, turismo nacional, turismo internacional).

La ubicación en la matriz de cada segmento de mercado se realiza de forma cualitativa teniendo en cuenta los criterios que aparecen en la tabla siguiente.

\begin{tabular}{|c|c|}
\hline $\begin{array}{l}\text { Importancia actual de los segmentos } \\
\text { de demanda turística }\end{array}$ & Expectativas de crecimiento futuro \\
\hline $\begin{array}{l}\text { - Volumen considerable. } \\
\text { - } \text { Número de pernoctaciones. } \\
\text { - Elevada estancia media. } \\
\text { - } \text { Elevado nivel de gasto. } \\
\text { - Baja estacionalidad. } \\
\text { - } \text { Rentabilidad social: generación de em- } \\
\text { pleo, recuperación del patrimonio, etc. }\end{array}$ & $\begin{array}{l}\text { - Previsible aumento del segmento de de- } \\
\text { manda con respecto al resto de segmen- } \\
\text { tos. } \\
\text { - Previsible interés del segmento de de- } \\
\text { manda por el turismo de interior. } \\
\text { - Previsible interés del segmento de mer- } \\
\text { cado por visitar el espacio turístico. }\end{array}$ \\
\hline
\end{tabular}

Fuente: Elaboración propia.

Por su parte, la distribución de los segmentos de mercado en la matriz da lugar a tres posibles situaciones: segmentos de mercado de prioridad 1 (las directrices deben fomentar al máximo la captación de esta demanda); segmentos de mercado de prioridad 2 (las actuaciones deben orientarse a mantener los niveles de esta demanda) y por último, segmentos de mercado de prioridad 3 (se desaconsejan actuaciones relevantes encaminadas hacia la captación de este tipo de demandas turísticas).

\subsection{Matriz atractivo del mercado-posición competitiva ${ }^{8}$}

La construcción de esta matriz obedece a la necesidad de identificar y priorizar las actuaciones en cada producto-mercado a partir de dos criterios fundamentales: el atractivo de mercado y la capacidad de competir, esto es, cada espacio trataría de captar los mercados más atractivos y en los que tiene mayores posibilidades de competir con éxito. Esta metodología fue desarrollada originalmente por el Boston Consultig Group y posteriormente adaptada al análisis regional turístico por Heath y Wall (1992) y empleada en el Plan de Espacios Turísticos de la Comunitat Valenciana realizado por el Instituto Universitario de Investigaciones Turísticas (2007).

En esta matriz se deben analizar todos los productos turísticos presentes y aquellos que pueden llegar a desarrollarse en un futuro inmediato en los espacios de interior (rural-relacional, rural-naturaleza, rural-retorno, residencial, cultural, activo, enológico, negocios, golf, congresos, salud y belleza, industrial, agroturismo, etc.).

La ubicación de cada producto-mercado en la matriz se realiza de forma cualitativa teniendo en cuenta los criterios que aparecen en la tabla siguiente.

8 Matriz ya existente (adaptación metodológica). 


\begin{tabular}{|l|ll|}
\hline \multicolumn{1}{|c|}{ Atractivo de mercado } & \multicolumn{1}{c|}{ Capacidad para competir } \\
\hline - $\begin{array}{l}\text { Volumen considerable. } \\
\text { - Alta tasa de crecimiento actual y buena } \\
\text { perspectiva de crecimiento futuro. }\end{array}$ & - $\begin{array}{l}\text { Cuota de mercado elevada. } \\
\text { Buen conocimiento del mercado. } \\
\text { Adaptación satisfactoria de la oferta a las } \\
\text { - Elevado nivel de gasto. }\end{array}$ & $\begin{array}{l}\text { exigencias del mercado. } \\
\text { Buen nivel de calidad de la oferta respec- } \\
\text { - } \begin{array}{l}\text { Demanda estable. } \\
\text { Rentabilidad social: generación de em- } \\
\text { pleo, recuperación del patrimonio, etc. }\end{array}\end{array}$ \\
\hline
\end{tabular}

Fuente: Elaboración propia a partir del Plan de Espacios Turísticos de la Comunitat Valenciana (2007).

La distribución de los productos-mercado en la matriz da lugar a tres posibles situaciones: productos-mercado de prioridad 1 que las directrices deben fomentar su máximo desarrollo; productos-mercado de prioridad 2 donde las actuaciones deben orientarse a mantener la situación actual o mejorarla; y productos-mercado de prioridad 3 donde se desaconsejan actuaciones relevantes.

\subsection{Matriz importancia de disfunciones-facilidad de resolución ${ }^{9}$}

La creación de esta matriz responde a la necesidad de identificar los problemas que afectan con una mayor incidencia al turismo de interior, señalando aquellos que presentan una mayor facilidad de resolución. La combinación de ambos factores servirá para priorizar sobre que disfunciones se debe actuar en primer lugar, optimizando de este modo el aprovechamiento y la rentabilidad económica, social y medioambiental de las inversiones públicas.

La ubicación de cada problema en la matriz se realiza de forma cualitativa-cuantitativa (importancia de las disfunciones) y cualitativa (facilidad de resolución) teniendo en cuenta los criterios que aparecen en la tabla siguiente.

\begin{tabular}{|l|l|}
\hline \multicolumn{1}{|c|}{ Importancia de las disfunciones } & \multicolumn{1}{c|}{ Facilidad de resolución } \\
\hline $\begin{array}{l}\text { Impactos medioambientales. } \\
\text { - Falta de rentabilidad económica en las } \\
\text { empresas. }\end{array}$ & $\begin{array}{l}\text { Resolución a corto y medio plazo. } \\
\text { Nivel de inversión reducido. } \\
\text { Aceptación social al cambio. }\end{array}$ \\
- Pérdida de identidad sociocultural. \\
$\begin{array}{l}\text { Pérdida de calidad de vida de la población } \\
\text { local. }\end{array}$ \\
- Insatisfacción de la demanda turística. \\
- Valoración de los agentes alta $(>60 \%)$. \\
- Valoración de los agentes media $(40-60 \%)$. \\
- Valoración de los agentes baja $(20-40 \%)$.
\end{tabular}

Fuente: Elaboración propia.

9 Matriz creada por el autor (aportación metodológica). 
La distribución de los segmentos de mercado en la matriz da lugar a tres posibles situaciones: disfunciones de prioridad 1 (las inversiones públicas deben centrarse prioritariamente en la resolución de estos problemas); disfunciones de prioridad 2 (las inversiones públicas deben orientarse hacia resolución de estos problemas, pero sin que ello suponga una inversión de fondos públicos excesiva); y disfunciones de prioridad 3 (las inversiones públicas deben orientarse hacia la minimización de estos problemas).

\subsection{Matriz actividades turísticas-impactos medioambientales ${ }^{10}$}

La creación de esta matriz múltiple basada en la desarrollada por Boch et. Al. (1998), responde a la necesidad de identificar los impactos derivados de la actividad turística (diferentes tipologías de alojamiento reglado, segundas residencias, infraestructuras de comunicación, eléctricas e hídricas, presencia de vertidos, campos de golf y actividades lúdicas, etc.), sobre el medio ambiente de espacios interiores (aguas continentales, ecosistemas terrestres y calidad atmosférica), a fin de establecer posibles mecanismos de prevención y minimización. En este caso, los criterios de valoración se ciñen exclusivamente a la identificación empírica y sumatorio de impactos ambientales sobre posibles receptores preestablecidos.

\section{APLICACIÓN DE LA PROPUESTA METODOLÓGICA AL INTERIOR DE ALICANTE}

\subsection{Aplicación de la matriz DAFO sobre el interior de Alicante}

El presente diagnóstico DAFO se ha nutrido de las aportaciones procedentes de colectivos empresariales a través de las dinámicas de grupo desarrolladas en el marco de las primeras y segundas Jornadas Empresariales de Turismo de la Costa Blanca. Estas jornadas fueron organizadas por la Cámara Oficial de Comercio, Industria y Navegación de Alicante y el Instituto Universitario de Investigaciones Turísticas de la Universidad de Alicante, celebrándose en 2008 y 2009. En concreto, la primera mesa de trabajo abordó específicamente el tema de los alojamientos rurales, mientras que en la segunda se trató de forma conjunta el turismo de interior, dando con ello cabida a las empresas de turismo activo y aventura.

De las conclusiones de las mesas de turismo de interior se desprende que mayoritariamente, los empresarios coinciden en que la situación actual de los alojamientos rurales de la provincia de Alicante es francamente negativa. Esta opinión responde a la escasa rentabilidad económica de este tipo de establecimientos y a las grandes dificultades que tienen los empresarios para amortizar las fuertes inversiones que han realizado en sus alojamientos.

10 Matriz ya existente (adaptación metodológica). 
Figura 1

DIAGNÓSTICO DAFO DEL TURISMO DE INTERIOR ALICANTINO

\begin{tabular}{|c|c|}
\hline DEBILIDADES & AMENAZAS \\
\hline $\begin{array}{l}\text { - Tardío despegue de la oferta turística. } \\
\text { - Escasa promoción de fiestas y tradiciones. } \\
\text { - Fuerte estacionalidad de la demanda. } \\
\text { - Corta duración de estancias. } \\
\text { - Inadaptación recursos patrimoniales al consumo } \\
\text { turístico. } \\
\text { - Falta de servicios de información turística. } \\
\text { - Falta de rentabilidad en negocios turísticos. } \\
\text { - Baja contratación laboral. } \\
\text { - Escaso porcentaje de demanda extrajera. } \\
\text { - Falta de estandarización y profesionalización en } \\
\text { oferta. } \\
\text { - Alojamientos de tipo individual (sin comidas). } \\
\text { - Falta de asociacionismo empresarial e insufi- } \\
\text { ciente gestión. }\end{array}$ & $\begin{array}{l}\text { - Promoción puntual, plural y espontánea. } \\
\text { - La marca Costa Blanca resulta insuficiente. } \\
\text { - Conflictos políticos dificultan acuerdos supra- } \\
\text { muncipales. } \\
\text { - Incapacidad para crear rutas turísticas operati- } \\
\text { vas. } \\
\text { - Fracaso Central de Reservas (desconfianza). } \\
\text { - Inadaptación de la regulación sobre alojamiento } \\
\text { turístico rural. } \\
\text { - Abandono de la Q del ICTE. } \\
\text { - Insuficiente señalización e infraestructuras co- } \\
\text { municación. } \\
\text { - Proyectos de macrourbanización y campos de } \\
\text { golf. } \\
\text { - Efectos crisis económica. } \\
\text { - Competencia de nuevos destinos turísticos. } \\
\text { - Cambio climático. }\end{array}$ \\
\hline FORTALEZAS & OPORTUNIDADES \\
\hline $\begin{array}{l}\text { - Establecimientos de alojamiento nuevos. } \\
\text { - Progresivo aumento de la oferta reglada. } \\
\text { - Empresarios con formación complementaria. } \\
\text { - Fácil promoción a través de Internet. } \\
\text { - Buena relación calidad-precio. } \\
\text { - Abundancia de recursos patrimoniales. } \\
\text { - Riqueza y proximidad al medio natural. } \\
\text { - Gastronomía tradicional. } \\
\text { - Autenticidad (artesanías). } \\
\text { - Tranquilidad. } \\
\text { - Trato personalizado. } \\
\text { - Temperaturas suaves en verano. }\end{array}$ & $\begin{array}{l}\text { - Flexibilidad y fragmentación de las vacaciones. } \\
\text { - Búsqueda de autenticidad en la demanda. } \\
\text { - Preocupación medioambiental en la sociedad. } \\
\text { - Generalización del asociacionismo. } \\
\text { - Captación de turistas extranjeros. } \\
\text { - Captación de nuevos turistas nacionales. } \\
\text { - Irradiación de flujos turísticos del litoral. } \\
\text { - Aprovechamiento de innovaciones tecnológicas. } \\
\text { - Confederación de Turismo de Interior de la CV. } \\
\text { - Club de Producto del Turismo de Interior. } \\
\text { - Marca Costa Blanca Interior. } \\
\text { - OPEN APSS de INVATTUR. } \\
\text { - Ejecución de planes estratégicos supramunici- } \\
\text { pales. }\end{array}$ \\
\hline
\end{tabular}

Fuente: Elaboración propia.

\subsection{Aplicación de la matriz potencial de los recursos turísticos-interés de la demanda sobre el interior de Alicante}

En el contexto actual los tres recursos fundamentales sobre los que se debe apoyar la actividad turística en el interior de Alicante son los espacios naturales, los monumentos y museos y la gastronomía (vid. Fig. 2). Sin embargo, también se pueden explotar otro tipo de recursos, aunque ello sí, sin perder de vista que en la actualidad están jugando todavía un papel complementario. 
Las fiestas son un recurso turístico excesivamente puntual que puede concentrar a la demanda únicamente en cortos espacios de tiempo. Además, en la mayoría de las ocasiones las fiestas están pensadas para el disfrute de los vecinos de la localidad o a lo sumo, de localidades próximas. Este hecho hace que el turista no comprenda las festividades y que en consecuencia no se haga partícipe de ellas.

La artesanía y las actividades deportivas, por el de momento, están jugando un mero papel secundario en la experiencia vacacional del turista. Sin embargo, ambos atractivos pueden jugar un papel prioritario en un futuro si se crea una oferta adecuada y vinculada a los recursos culturales y naturales que presenta el medio interior.

La playa, por ahora, juega un papel testimonial para el interior de Alicante. Sin embargo, el futuro pasa por la complementariedad de los productos y la combinación de estancias en el interior y el litoral (paquetes vacacionales).

Actualmente, la compra de productos (agroalimentarios, recordatorios, etc.), los eventos y los centros de ocio y entretenimiento, salvo en meritorias excepciones, todavía carecen de una adecuada organización y gestión profesional para articularse como verdaderos reclamos turísticos.

Figura 2

MATRIZ POTENCIAL DE LOS RECURSOS TURÍSTICOS DEL INTERIOR DE ALICANTE-INTERÉS DE LA DEMANDA

\section{INTERÉS DE LA DEMANDA}

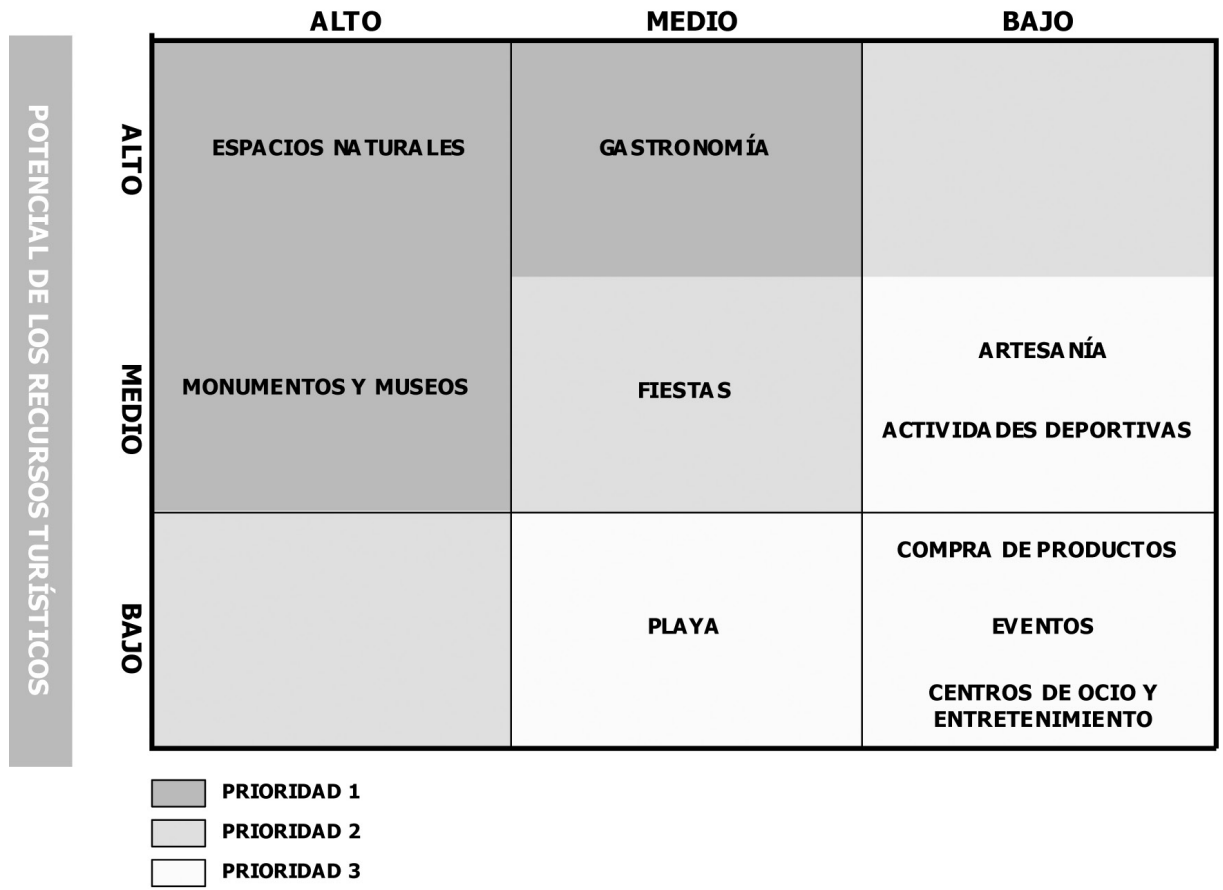

Fuente: Elaboración propia a partir datos procedentes de las encuestas Tourist Info (2008-09) a los municipios interiores de la provincia de Alicante. Conselleria de Turisme. 


\subsection{Aplicación de la matriz importancia actual de los segmentos de demanda-expectativas de crecimiento futuro sobre el interior de Alicante}

En base a una segmentación de mercado por edad, los turistas más importantes para el interior de Alicante son los de mediana edad y es previsible que mantengan un nivel de crecimiento futuro medio (vid. Fig. 3). Los jóvenes, en la actualidad, todavía no representan un volumen significativo para el turismo de interior, ya que se dedican básicamente al excursionismo y a las pernoctaciones en alojamientos económicos. Sin embargo, es previsible que en un futuro y gracias a la incorporación progresiva de ofertas complementarias de tipo deportivo y aventura, este segmento de demanda juegue un papel cada vez más significativo en el turismo de interior. Por su parte, los turistas de la tercera edad todavía prefieren destinos baratos y masivos preferentemente ubicados en el litoral. No obstante, si se tienen en cuenta las previsiones futuras, la demanda actual de mediana edad acostumbrada a visitar el medio interior pasará a ser la tercera edad del futuro y seguirá demandando este tipo de turismo, pero eso sí, con unos niveles de calidad y sofisticación cada vez superiores.

Figura 3

MATRIZ IMPORTANCIAACTUAL DE LOS SEGMENTOS DE DEMANDA-EXPECTATIVAS DE CRECIMIENTO FUTURO EN EL INTERIOR DE ALICANTE

EXPECTATIVAS DE CRECIMIIENTO FUTURO

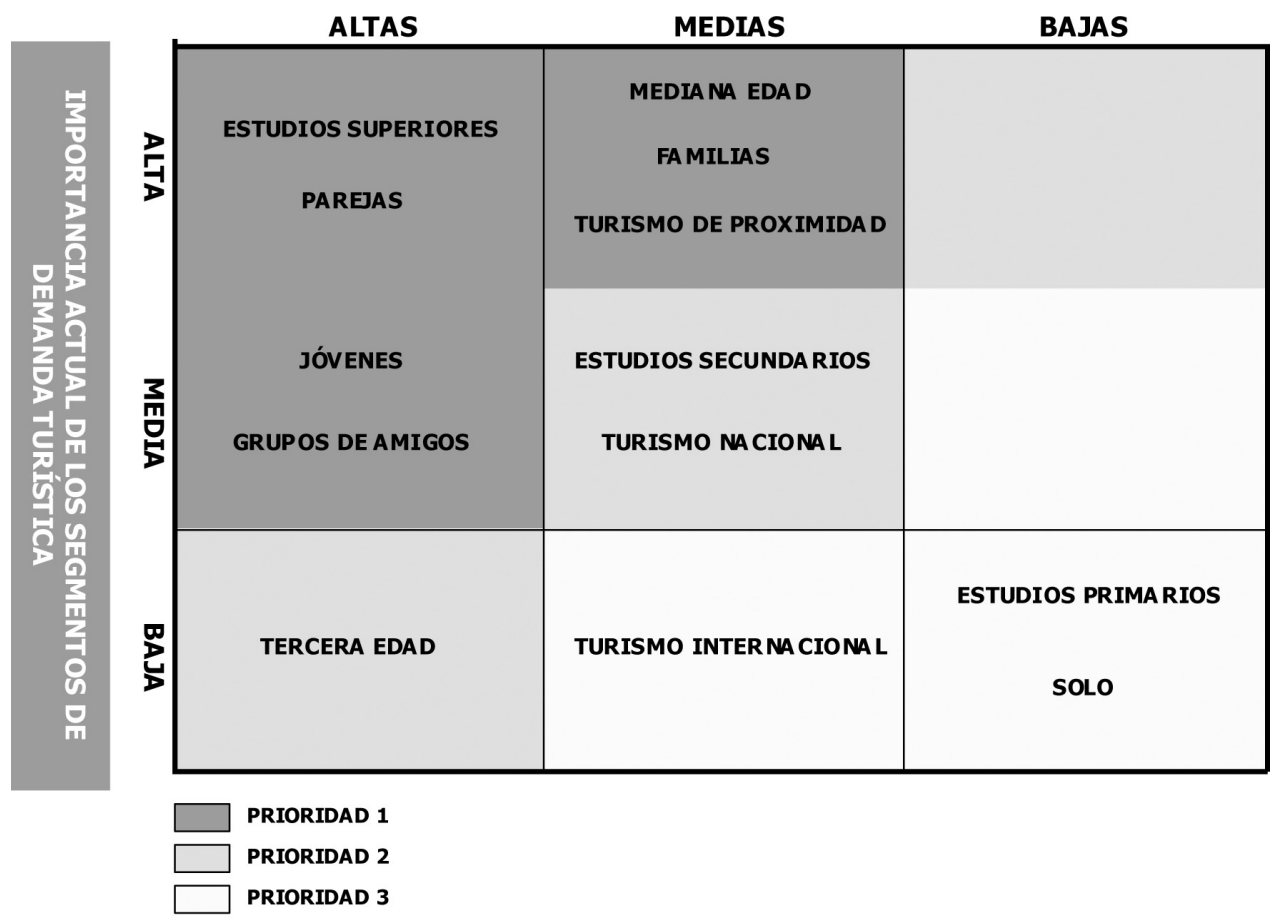

Fuente: Elaboración propia a partir del análisis empírico de las variables seleccionadas. 
Según la segmentación de mercado por nivel de estudios, los turistas que más visitan el medio interior alicantino son los de estudios superiores. Estos turistas son los más exigentes y los que buscan mayores niveles de autenticidad, singularidad y calidad en la práctica del turismo. En este sentido, es previsible que este segmento de demanda siga manteniendo en el futuro las mismas exigencias y por lo tanto el interés por visitar el medio interior. Los turistas con estudios secundarios son en la actualidad bastante significativos y en el futuro seguramente mantendrán sus niveles de acceso al medio interior. Por último, los turistas con estudios primarios son los que menos pernoctan en el interior, aunque si que realizan excursiones diarias. Además, es previsible que esta tendencia se mantenga en el futuro mientras los alojamientos de interior conserven sus precios por encima de otros destinos vacacionales más convencionales (sol y playa, turismo urbano, etc.).

Si el análisis se centra en la segmentación de mercado por tipo de acompañantes, cabe destacar que actualmente el turismo familiar y de parejas es el que más acude al interior de Alicante. En el futuro resulta previsible que ambos segmentos se mantengan, o hasta incluso, que el turismo de parejas aumente si sigue la tendencia actual de retrasar el nacimiento de hijos hasta más allá de los 30 años o el número de hijos por pareja. En este sentido, el estado cada vez más saludable de las personas de la tercera edad aumenta la posibilidad de dejar los hijos con sus abuelos y disfrutar del turismo de interior solamente en pareja. Por su parte, los grupos de amigos que visitan en la actualidad el medio interior pueden aumentar si se incrementa el número de solteros y divorciados, o simplemente, si se aumenta la oferta complementaria (actividades deportivas y de aventura) y se ofrecen alojamientos de bajo precio (campings, albergues, refugios, etc.) a la población más joven. Por el contrario, los turistas que viajan solos, presentan una importancia reducida y es de esperar que el futuro lo sigan haciendo dado que la tranquilidad del medio interior no propicia excesivamente el hecho de conocer a otros turistas como en el caso de los cruceros, los circuitos organizados, el sol y playa, etc.

Por último, según la segmentación del mercado por origen de la demanda, los turistas que más acuden al interior de Alicante son los que viven en el entorno próximo (misma provincia, Valencia, Albacete y Murcia). En el futuro es previsible que la demanda de proximidad se mantenga, aunque sin aumentar la estancia media ni reducir la estacionalidad. Actualmente, los turistas nacionales van aumentando progresivamente conforme se va conociendo mejor el interior de Alicante a través de Internet y el boca-oído. En el futuro es previsible que se mantenga esta tendencia sobre todo en aquellos turistas que vienen de Madrid, Andalucía y Cataluña. Por último, los turistas procedentes del extranjero siguen siendo una minoría en el interior de Alicante y lo seguirán siendo a menos que se generalicen progresivamente cambios en la oferta turística y la promoción. De todos modos, a pesar de esta prospectiva poco positiva, la captación de demanda turística internacional es una de las principales prioridades del turismo de interior de Alicante, sobre todo si se pretende reducir la estacionalidad y aumentar la ocupación y la estancia media. 


\subsection{Aplicación de la matriz atractivo de mercado-posición competitiva sobre el interior de Alicante}

En esta matriz se han analizado los principales productos turísticos presentes en el interior de Alicante: turismo relacional, turismo de naturaleza, turismo de retorno, turismo residencial, turismo cultural, turismo activo, turismo enológico, turismo de negocios, turismo de golf, turismo de congresos, turismo de salud y belleza, turismo industrial y agroturismo.

Figura 4

MATRIZ ATRACTIVO DEL MERCADO-POSICIÓN COMPETITIVA DEL TURISMO DE INTERIOR DE ALICANTE

\section{ATRACTIVO DELL MERCADO}

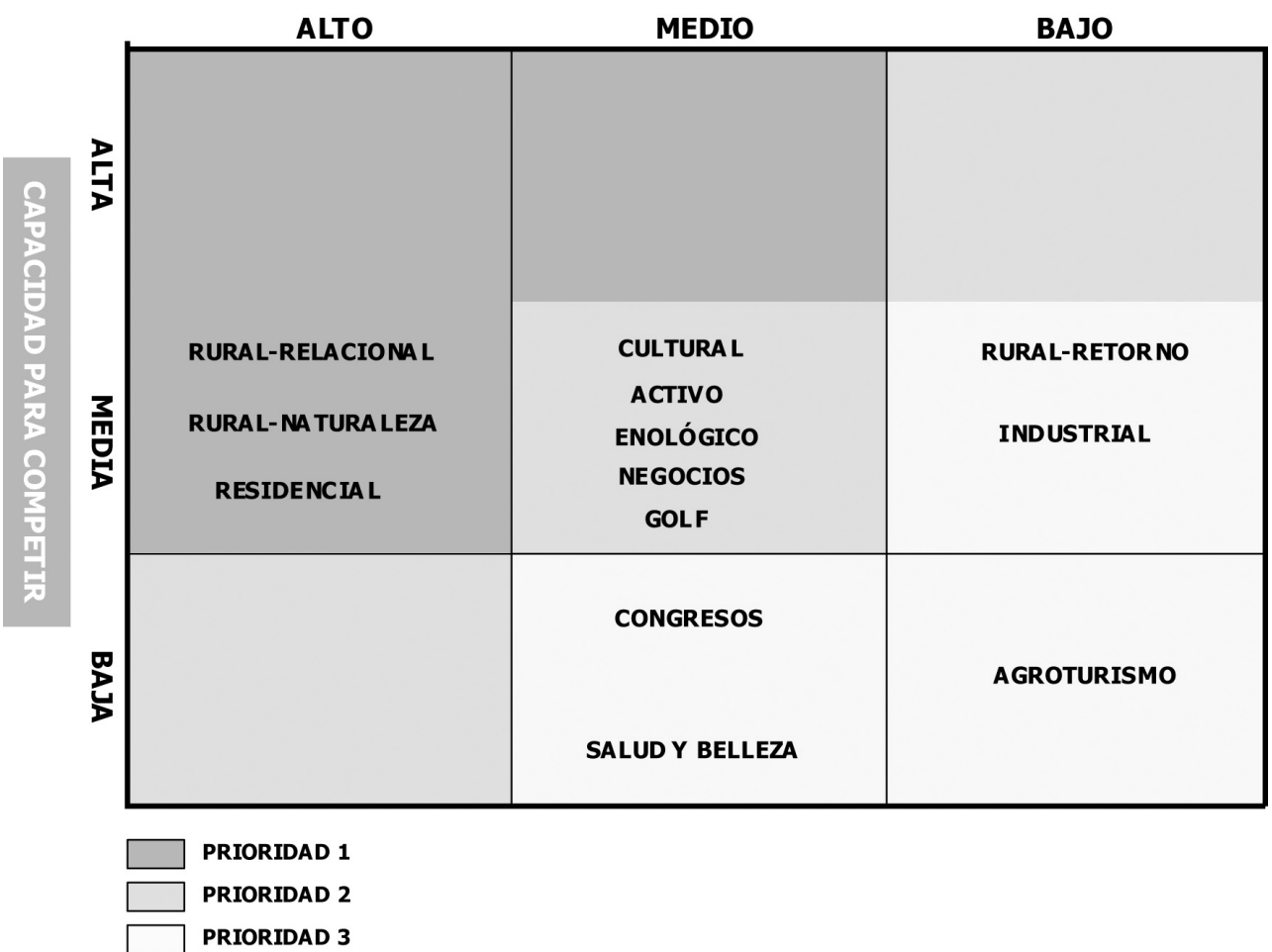

Fuente: Elaboración propia a partir de la metodología del Plan de Espacios Turísticos de la Comunitat Valenciana y el análisis empírico de las variables seleccionadas.

El producto rural-relacional se concentra básicamente en los municipios más pequeños, donde la impronta rural está menos desvirtuada. Los turistas buscan en el medio rural una conjunción de reclamos (entorno natural atractivo, patrimonio histórico, gastronomía, artesanía, folclore, etc.), pero sobre todo, la autenticidad y la idiosincrasia sociocultural. Asimismo, se busca un medio distinto al urbano cotidiano para el desarrollo de relaciones familiares y de amistad, mayoritariamente entre jóvenes y parejas con niños. De momento, 
esta demanda acude en periodos vacacionales veraniegos, puentes y fines de semana, a los municipios con mayor oferta rural (La Vall d'Alcalà, Biar, Agres, Penàguila, Vall de Gallinera, Vall de Laguar, Tárbena, Castell de Castells, etc.) (vid. Mapa 1). Aunque el volumen de demanda en temporada alta es muy elevado, la estacionalidad es la tónica dominante. Sin embargo, es previsible que la demanda se incremente en un futuro próximo y se reduzca paulatinamente la estacionalidad, gracias básicamente al fraccionamiento de las vacaciones pagadas y la llegada progresiva de turistas extranjeros.

El nivel de gasto va en función del perfil de la demanda y el alojamiento que se utilice, pero en general se buscan servicios de calidad y se paga por ellos. De momento, este producto únicamente supone una fuente de ingresos complementaria para la población oriunda y no repercute mucho sobre la generación de empleo estable. Hay que tener también en cuenta que este tipo de turismo contribuye muy favorablemente a la recuperación del patrimonio, el embellecimiento de los pueblos y lo que es todavía más importante, el mantenimiento de la población local.

Por otro lado, aunque la capacidad para competir es todavía media, existe un gran margen de mejora gracias al gran esfuerzo que se está realizando en la profesionalización del sector y el apoyo a la inversión. Para ser más competitivos se deberá apostar por la comercialización del producto en el extranjero y la uniformización de las calidades en los establecimientos y los servicios.

El producto rural-naturaleza se centra en la visita de espacios naturales protegidos, en este caso, fundamentalmente los Parques Naturales (Sierra de Mariola, Font Roja y El Fondó). La utilización de otras áreas con sierras declaradas LIC va en función del conocimiento del espacio por parte de la demanda o su descubrimiento a partir del consumo del producto rural-relacional.

Para el consumo de este producto resulta imprescindible una buena red de senderos de pequeño recorrido (PR). En la parte noroccidental del espacio existen un gran número senderos PR, pero en la parte nororiental y meridional se puede ampliar notablemente su presencia. Resulta previsible que el mercado para este producto crezca progresivamente, dado el creciente interés social que despierta el medioambiente y naturaleza.

En el momento actual, la capacidad para competir de este producto es media, pero si se aumentan las superficies protegidas bajo la figura de Parque Natural o Paraje Natural y se mantienen, promocionan debidamente y crean nuevas infraestructuras forestales (áreas recreativas, cabañas, refugios, fuentes, señalizaciones, etc.), las posibilidades para competir con éxito dada la benignidad del clima y la belleza de los entornos, son francamente extraordinarias.

El turismo rural de retorno no supone un gran volumen de visitantes, al menos en el sur y la mitad noroccidental del espacio donde la población no ha abandonado los municipios gracias al empleo industrial, el comercio y la agricultura de vanguardia. No obstante, se puede observar un cierto número de veraneantes en los municipios más pequeños de la mitad nororiental, que tradicionalmente han tenido una mayor dedicación agrícola (secano y agricultura de subsistencia) y donde el proceso de éxodo rural ha sido más intenso.

El producto residencial en el interior de Alicante viene importado del medio litoral a partir del agotamiento del suelo y la masificación poblacional. Este espacio resulta cada vez más atractivo para la demanda por su proximidad al litoral, sobre todo en la Hoya de Casta- 


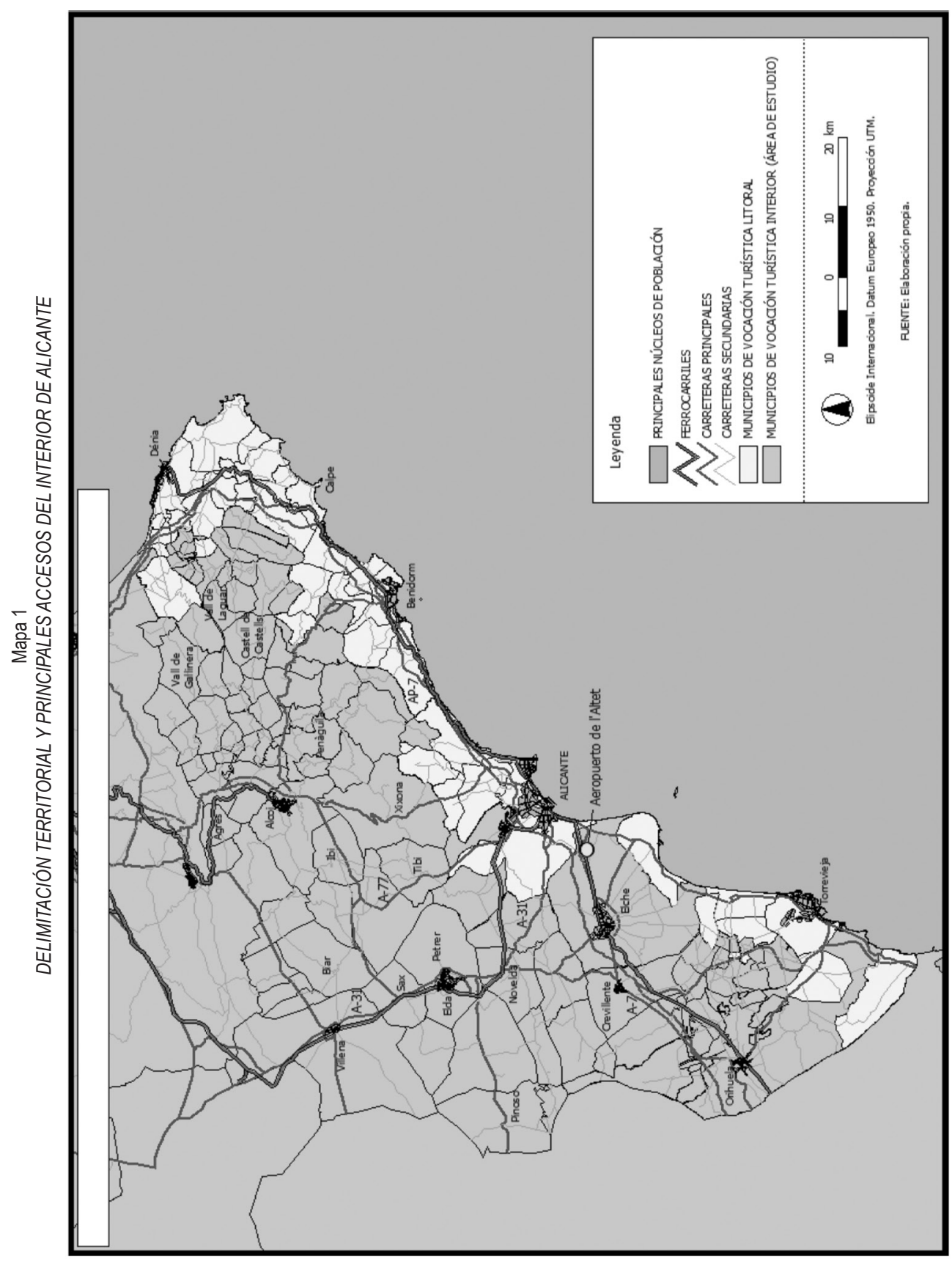


lla, el corredor del Vinalopó y la Vega Baja del Segura, donde las vías de comunicación son más rápidas. Este producto tiene muchas posibilidades de competir con éxito, ya que unido a la proximidad del litoral, los residentes pueden beneficiarse de precios del suelo más económicos y disfrutar de un medio más saludable (menos contaminación, menor saturación, mayor tranquilidad, mejor gastronomía, etc.). Sin embargo, se debe puntualizar que el desarrollo residencial de los municipios interiores no se debe ejecutar a partir de recalificaciones de suelos y construcción de nuevas urbanizaciones que generan graves disfunciones sociales y ambientales, sino a través de la rehabilitación de casas abandonadas en los centros históricos y desarrollos urbanos ordenados y siempre conformes a las previsiones de los Planes Generales.

El turismo activo es un producto emergente con una buena perspectiva de crecimiento futuro y que contribuye positivamente a la generación de empleo y a la conservación del medio natural. A pesar de ello, la oferta actual está confinada en los municipios de mayor tamaño (Elche, Alcoi, Castalla, Biar, Cocentaina, Villena, Novelda, Petrer, Elda, etc.). Estos municipios son los que más han incentivado la oferta complementaria y presentan una mayor profesionalización de cara a las expectativas de la demanda. No obstante, las posibilidades para competir de este producto son francamente mejorables, si se crean nuevas empresas que amplíen la oferta aprovechando los recursos naturales de la mitad nororiental del espacio. Pero también, si se comercializan nuevas actividades que trasciendan el excursionismo terrestre (Educativas: aulas de la naturaleza; Aéreas: saltos o vuelos desde relieves de más de 1.000 metros de altitud; Acuáticas: puesta en valor de embalses).

El turismo cultural depende de la temporalidad de eventos como la feria de Cocentaina, fiestas como los Moros y Cristianos de Alcoi, El Misteri d'Elx o la Semana Santa de Orihuela, a la hora de generar volúmenes significativos de turistas. Sin embargo, la capacidad para competir de este producto está aumentando progresivamente gracias a la creación de nuevos museos y la rehabilitación y puesta en valor de los recursos histórico-artísticos de los municipios de interior (centros históricos, castillos, yacimientos arqueológicos, etc.).

El interior de Alicante presenta una larga tradición vitivinícola en las comarcas del Vinalopó y El Comtat, que puede materializarse en la consecución de un producto enoturístico complementario o incluso finalista, sobre todo tras la puesta en marcha de la Ruta del Vino de la Denominación de Origen Alicante, que ha sido impulsada desde el municipio de Pinoso. El atractivo para el mercado de este producto está aumentando progresivamente al vincularse con la calidad de vida, la salud y la exclusividad. De momento, la capacidad para competir como producto turístico es todavía media-baja, pero es previsible que esta capacidad vaya aumentando conforme aumente el grado organizativo de la Ruta Turística.

El turismo de negocios en el interior de Alicante puede representar una buena alternativa para aumentar las pernoctaciones durante los días de entre semana, sobre todo en las áreas más industrializadas y con mayor dinámica comercial (Hoya de Castalla, Alcoi y Cocentaina, corredor del Vinalopó, Elche y Crevillent, etc.). Pero para que esto se materialice se necesita aumentar la oferta hotelera, sobre todo en aquellos municipios más accesibles por carretera.

El turismo de congresos queda fundamentalmente supeditado a Elche y en menor medida y de forma incipiente a Alcoi. De todos modos, este tipo de turismo podría dinamizar el entorno de estas ciudades a través de oferta complementaria que enriquezca la experiencia de los congresistas (gastronomía, artesanía, naturaleza, ocio activo, cultura, enología, etc,). 
El turismo de golf presenta cierta capacidad para competir en la parte meridional del espacio que presenta cuatro campos de golf (Alenda en Monforte del Cid y Campoamor, Ramblas de Orihuela y Villamartín en Orihuela). Esta competitividad podría aumentar si se crea algún nuevo campo de golf en el corredor del Vinalopó. En cualquier caso, no resulta recomendable crear campos de golf en otras zonas del espacio, sobre todo en aquellas más montañosas donde el campo quedaría desvinculado de otras ofertas de golf, se modificaría el paisaje rural y se alteraría la idiosincrasia sociocultural de los pueblos más pequeños, sobre todo si el campo de golf se vincula a nuevos desarrollos urbanísticos.

El turismo de salud aunque en la actualidad está cada vez más de moda por el culto al cuerpo y la necesidad de la sociedad de desconectar del stress diario. Todavía no se ha desarrollado suficientemente en el interior de Alicante por la falta de recursos naturales (aguas termales o mineromedicinales) o la falta de iniciativas empresariales, salvo algún ejemplo aislado de iniciativas de colaboración entre alojamientos y gimnasios locales.

El turismo industrial aunque no dispone de un gran mercado en estos momentos, puede llegar a captar el interés de la demanda turística dada su singularidad frente al enorme abanico de competidores que tienen el resto de productos. Cabe manifestar, que este producto no se ha desarrollado todavía por completo en el interior alicantino, pero sin embargo, sí dispone de suficientes elementos para que pueda hacerlo en un futuro inmediato (patrimonio industrial de Alcoi, Museo del Joguet de Ibi, Museo de la Muñecas de Onil, Museu del Paper de Banyeres de Mariola, Museo del Calzado de Elda, Museo del Turrón de Jijona, industrias de calzado de Elche, industrias de alfombras de Crevillent, cerámicas de Agost y Biar, etc.).

La rentabilidad social de este producto puede ser significativa, sobre todo si se tiene en cuenta la situación de crisis a la que se enfrenta la industria manufacturera. No obstante, cabe puntualizar que resulta conveniente apostar por este tipo de producto en estancias breves, dada la aparente puntualidad de los recursos a explotar o bien de forma complementaria con otros productos finalistas.

El agroturismo todavía no se ha desarrollado suficientemente en el interior de Alicante a pesar de presentar una buena perspectiva de crecimiento y un notable beneficio sociocultural en la generación de rentas complementarias o en la conservación del paisaje tradicional. Los municipios, sobre todo de la mitad nororiental y meridional, disponen de una larga tradición agrícola en cultivos de secano y hortalizas, respectivamente. Esta vocación agrícola puede ser aprovechada por la actividad turística si media el interés de las cooperativas agrarias.

\subsection{Aplicación de la matriz importancia de las disfunciones-facilidad de resolución sobre el interior de Alicante}

A partir de los datos recabados en las encuestas postales realizadas en el marco del Plan de Espacios Turísticos de la Comunidad Valenciana y el desarrollo de esta nueva matriz, se pueden agrupar las disfunciones detectadas en el turismo de interior alicantino en tres niveles de prioridad para atender a su posible resolución (vid. Fig. 5). 
Figura 5

MATRIZ IMPORTANCIA DE LAS DISFUNCIONES DEL TURISMO DE INTERIORALICANTINO-FACILIDAD DE RESOLUCIÓN

\section{FACILIDAD DE RESOLUCIÓN}

\begin{tabular}{|c|c|c|c|}
\hline & ALTA & MEDIA & BAJA \\
\hline$\underset{D}{\stackrel{7}{\mathrm{~S}}}$ & $\begin{array}{l}\text { FALTA CONCIENCIA CIÓN } \\
\text { IMPORTA NCIA TURISMO } \\
\text { FORMACIÓN DEL PERSONAL } \\
\text { FALTA MANO DE OBRA } \\
\text { PRECARIEDAD LABORAL } \\
\text { EMPLEA DOS }\end{array}$ & $\begin{array}{l}\text { FALTA DE ALOJAMIENTO } \\
\text { FALTA OF. COMPLEMENTARIA } \\
\text { FALTA OF. LÚDICA } \\
\text { FALTA DINAMISMO } \\
\text { EMPRESARIAL } \\
\text { RIESGO INCENDIO FORESTAL }\end{array}$ & $\begin{array}{l}\text { FALTA TRA NSPORTE } \\
\text { PÚBLICO }\end{array}$ \\
\hline $\begin{array}{l}\mathbf{3} \\
\text { 劣 } \\
\end{array}$ & $\begin{array}{l}\text { ESCASA VALORACIÓN DE LA } \\
\text { CULTURA LOCAL } \\
\text { GENERACIÓN DE RESIDUOS } \\
\text { TRÁFICO Y APARCAMIENTO } \\
\text { VERTIDOS INCONTROLADOS }\end{array}$ & FUERTE ESTACIONALIDAD & $\begin{array}{l}\text { FALTA INFRA ESTRUCTURAS } \\
\text { SA NITARIAS } \\
\text { INSEGURIDA D CIUDA DA NA }\end{array}$ \\
\hline 罗 & $\begin{array}{l}\text { CRECIMIENTO } \\
\text { URBA NÍSTICO EXCESIVO } \\
\text { DÉFICIT ZONAS VERDES } \\
\text { DETERIORO DEL PAISAJE }\end{array}$ & $\begin{array}{l}\text { DETERIORO IMA GEN } \\
\text { URBA NA } \\
\text { DÉFICIT ÁREAS } \\
\text { RECREA TIVAS }\end{array}$ & $\begin{array}{c}\text { DÉFICIT INFRA ESTRUCTURAS } \\
\text { DE COMUNICA CIÓN } \\
\text { AGUA ABASTECIMIENTO } \\
\text { URBA NO } \\
\text { DÉFICIT DEPURACIÓN } \\
\text { AGUAS }\end{array}$ \\
\hline
\end{tabular}

PRIORIDAD 1

PRIORIDAD 2

PRIORIDAD 3

Fuente: Elaboración propia a partir de los datos recogidos en las cuestionarios postales a los agentes públicos del interior de Alicante (Plan de Espacios Turísticos de la Comunitat Valenciana). Conselleria de Turisme.

\section{- Prioridad 1}

Entre los problemas más importantes para el turismo de interior alicantino, que presentan una mayor facilidad de resolución, aparecen aquellas disfunciones que se pueden resolver con campañas de concienciación ciudadana (falta de concienciación local sobre las importancia de la actividad turística) y medidas formativas y orientativas de los trabajadores y los empresarios (formación adecuada del personal de base y de los empresarios para una mejor gestión de los establecimientos, que pueda incluso, minimizar la precariedad laboral de los empleados).

Entre los problemas más importantes que evidencian una facilidad de resolución media se encuentran aquellos que requieren inversiones privadas significativas y subvenciones públicas para dinamizar el tejido empresarial y crear nuevas ofertas (alojamiento, oferta complementaria, oferta lúdica y de entretenimiento, etc.). En este grupo se incluye también el riesgo de incendio forestal, no tanto por lo costoso de las campañas de concienciación y 
vigilancia que en muchos casos son realizadas por voluntarios, sino por los problemas que supone controlar los amplios espacios forestales que tiene el interior de Alicante.

Los últimos problemas considerados de primera prioridad son aquellos que aunque presentan una importancia media evidencian una fácil resolución. Entre ellos se encuentran problemas que se pueden resolver con campañas de concienciación local (escasa valoración de la cultura local) y problemas que se pueden solucionar a través de mecanismos de gestión eficaz de los servicios e infraestructuras públicas (generación de residuos, problemas de tráfico y aparcamiento, existencia de vertidos incontrolados).

\section{- Prioridad 2}

En esta agrupación se incluyen problemas importantes de difícil solución como la falta de transporte público en un medio rural que hace difícil la rentabilidad de este tipo de empresas; problemas de importancia media y solución también intermedia como la fuerte estacionalidad que depende de múltiples factores (potencial turístico del municipio, tipología, calidad y tamaño de la oferta, disponibilidad de la oferta complementaria, perfil de la demanda, promoción y comercialización, etc.), pero que se puede minimizar el efecto de la disfunción si se lleva a cabo una gestión turística profesional del municipio y de las empresas; y problemas poco importantes para el caso concreto del interior de Alicante, pero que presentan soluciones menos costosas como pueden ser medidas de control, vigilancia, restricción y sanción (crecimiento urbanístico excesivo y deterioro del paisaje) o la creación de nuevos servicios e infraestructuras municipales de menor coste económico (creación de zonas verdes).

\section{- Prioridad 3}

Las disfunciones de tercera prioridad se corresponden con problemas de importancia media y difícil solución por la gran inversión que requieren (falta de infraestructuras sanitarias, inseguridad ciudadana); problemas de escasa importancia para el interior de Alicante y solución intermedia como el deterioro de la imagen urbana y el déficit de áreas recreativas; y problemas poco importantes de costosa solución como el déficit de infraestructuras de comunicación, el agua para abastecimiento urbano y el déficit de depuración de aguas.

\subsection{Aplicación de la matriz actividades turísticas-impactos medioambientales sobre el interior de Alicante}

Los hoteles y los albergues se erigen como los elementos turísticos más perniciosos para el medio ambiente por cuanto suponen una mayor concentración de infraestructuras y servicios ofrecidos al visitante susceptibles de provocar impactos de todo tipo (vid. Fig. 6). De un modo similar, también provocan impactos destacables las urbanizaciones turísticoresidenciales, aunque en este caso los efectos sobre la calidad atmosférica son inferiores.

Por su parte, los campings y los campos de golf ejercen impactos medioambientales de similar nivel. Los primeros inciden más sobre la calidad bacteriológica, las comunidades del suelo y los ruidos, mientras que los segundos afectan en mayor proporción a los poblamientos faunísticos, el suelo y los acuíferos. 
Entre las actividades realizadas por los turistas que provocan un mayor impacto medioambiental destaca sobre todo la práctica de deportes de aventura. La gran variedad de actividades deportivas y el gran número de medios que pueden afectar (aéreo, acuático, terrestre y subsuelo) hacen que su práctica deba de ser controlada y vigilada al máximo, sobre todo en aquellos espacios con ecosistemas más frágiles y vulnerables.

Figura 6

MATRIZ SOBRE IMPLANTACIÓN ACTIVIDADES TURÍSTICAS-GENERACIÓN IMPACTOS MEDIOAMBIENTALES EN EL INTERIOR DE ALICANTE

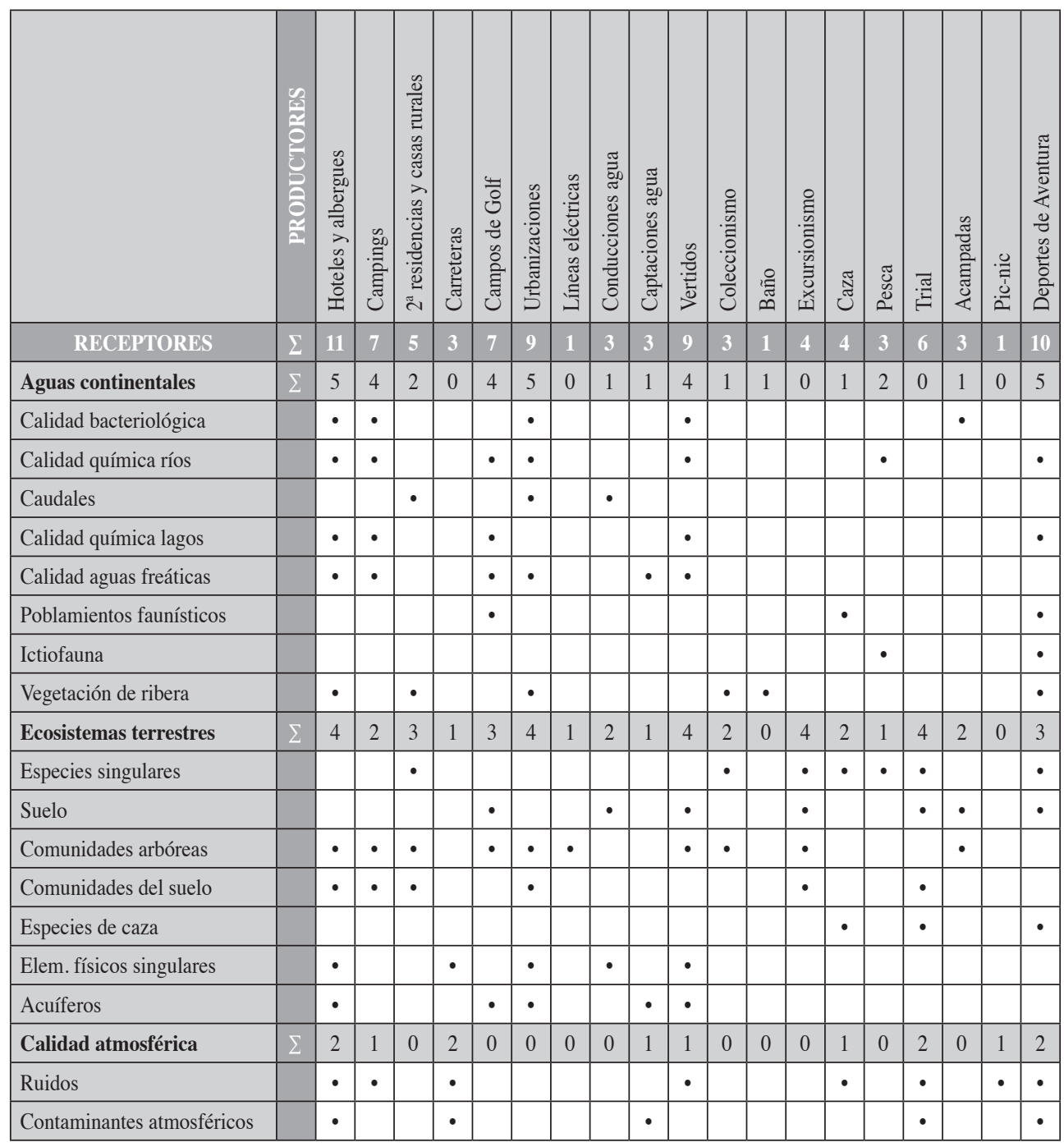

Fuente: Elaboración propia a partir de la metodología propuesta por BOCH et. Al. (1998) y el análisis empírico de las variables seleccionadas. 


\section{CONCLUSIONES}

A través de la presente investigación se ha pretendido adaptar y aportar nuevas herramientas metodológicas para la planificación estratégica en espacios turísticos de interior, que tradicionalmente han sido olvidados en favor del desarrollo de metodologías para la planificación de otros ámbitos turísticos con una mayor afluencia de visitantes, presencia de actividad económica y problemáticas derivadas (destinos masivos de sol y playa y destinos urbanos).

En definitiva, el desarrollo de matrices desempeña una función determinante en los procesos de planificación estratégica, ya sea a través del famoso diagnóstico DAFO, como por medio de otras matrices más específicas. A través de la aplicación de las matrices propuestas en este artículo se pueden definir de un modo más nítido y eficaz los objetivos prioritarios que deben alcanzarse a través de la planificación estratégica de los espacios turísticos de interior.

De este modo, para el caso concreto del interior de Alicante la matriz sobre potencial de los recursos turísticos-interés de la demanda, pone de manifiesto que las inversiones deben fomentar preferentemente la explotación razonable de los espacios naturales, pero también la gastronomía, los monumentos y museos. La matriz sobre importancia actual de los segmentos de demandaexpectativas de crecimiento futuro, identifica como segmentos de interés prioritario las parejas y los turistas con niveles de estudios superiores. La matriz atractivo de mercado-posición competitiva, apunta que las directrices en materia de planificación deben fomentar especialmente el desarrollo de los productos rural-relacional, rural-naturaleza y residencial (este último introduciendo las debidas cautelas en materia de ordenación del territorio). La matriz importancia de las disfunciones-facilidad de resolución, identifica como problemas de preferente atención la falta de concienciación sobre la importancia del turismo, la formación de personal, la falta de mano de obra y la precariedad laboral de los empleados. Por último, la matriz sobre actividades turísticasimpactos ambientales, señala que los alojamientos (hoteles y albergues) y la práctica de deportes de aventura, son las actividades turísticas que ejercen un mayor impacto sobre el medio y, por tanto, son las que deben tratar de desarrollarse con un mayor grado de control.

\section{BIBLIOGRAFÍA}

ANTÓN CLAVÉ, S. y GONZÁLEZ REVERTÉ, F. (2005): «Fundamentos de planificación territorial» en ANTÓN y GONZÁLEZ (Coord.): Planificación territorial del turismo. Editorial UOC, Barcelona, págs. 15-60.

BERNABÉ, A. y VIÑALS, M. J. (1999): «La planificación turística en los espacios naturales y rurales» en VIÑALS y BERNABÉ (Ed.): Turismo en espacios naturales y rurales. Ed. Universidad Politécnica de Valencia, Valencia. Págs. 174-192.

BOTE GÓMEZ, V. (1990): Planificación Económica del Turismo de una estrategia masiva a una artesanal. Editorial Trillas, México.

BOSCH CAMPRUBÍ, R., PUJOL MARCO, L., SERRA CABADO, J. y VALLESPINOS RIERA, F. (1998). Turismo y medio ambiente. Edita: Centro de Estudios Ramón Areces, Madrid.

BOULLON, R. (1989): Planificación turística. Ed. Trillas. México D. F.

BUTLER, R. (1980): «The Concept of a Tourist Area Cycle of Evolution: Implications for Management of Resources», en Canadian Geographer, vol. 24, nº 1, págs. 5-12. 
CHOY, D. J. L. (1992): «Life Cycle Models for Pacific Island Destinations», Journal of Travel Research (Invierno), vol. 30, n 3 págs. 26-31.

DÍAS, R. (2003): Planejamento do Turismo: política e desenvolvimento do turismo no Brasil. Atalas, Sau Paulo.

ESTEBAN, A. (1996): «El marketing turístico: la orientación de la actividad hacia el consumidor» en PEDREÑO (Dir.). Introducción a la economía del turismo en España. Ed. Civitas. Madrid. págs. 247-274.

GÓMEZ GARCÍA, O. (2009): «Análisis de entorno, segmentación y marketing del turismo rural» en CROBY, A. (Ed.): Re-inventando el turismo rural. Gestión y desarrollo. Editorial ALERTES. Barcelona, págs. 155-185.

GUNN, C. A. (1994): Tourism Planning. Basics Concepts Cases. Taylor \& Francis, United States of America. New York.

HEATH, E. y WALL, G. (1992): Marketing tourism destination: a strategic planning approach. Ed. Wiley, New York.

HORNER, S. Y SWARBROOKE, J. (1996): Marketing Tourism, Hospitality and Leisure in Europe. International Thomson Business Press, London.

INSKEEP, E. (1991): Planificación turística nacional y regional. OMT, Madrid.

IVARS BAIDAL, J.A. (2003): Planificación turística de los espacios regionales en España. Editorial Síntesis. Madrid.

KOTLER, P., HAIDER, D. y REIN, J. (1997): Mercadotecnia de localidades. Como atraer inversiones, industrias y turismo a ciudades, regiones y píises. Editorial Diana. México.

MCINTYRE, G. (1993): Sustainable Tourism Development: Guide for Local Planners. OMT. Madrid.

MURPHY, P. (1985): Tourism a community approach. Ed. Methuen. New York.

ORDUNA, F. J. (2002): «Turismo, patrimonio natural y medio ambiente», en Revista de Desarrollo Rural y Cooperativismo Agrario, N. . 4, págs. 95-130.

ORGANIZACIÓN MUNDIAL DE TURISMO (1999): Turismo: panorama 2020. Nuevas previsiones, OMT, Madrid.

PEARCE, D. (1988): Desarrollo turístico. Su planificación y ubicación geográfica. Ed. Trillas. México.

PUJOL, L. (1991): «Plan de desarrollo turístico de una zona», en Papers de Turisme, $\mathrm{n}^{\circ} 7$, págs. 25-37.

PULIDO, J. I. (2005): «Los retos del turismo rural en España. Orientaciones para la formulación de una política turística rural», en LÓPEZ GUZMÁN, T. y LARA, F. (dir.): Turismo sostenible. Un enfoque multidisciplinar e internacional. Servicio de Publicaciones de la Universidad de Córdoba, Córdoba, págs. 73-106.

RIVAS GARCÍA, J. (2006): La planificación turística. Septen Ediciones, Oviedo.

SMITH, S. (1991): Tourism analysis: a handbook. Longman Scientific and Technical. London. SOLSONA MONZONÍS, F. J. (2009): «La planificación turística en espacios rurales» en CROBY, A. (Ed.): Re-inventando el turismo rural. Gestión y desarrollo. Editorial ALERTES. Barcelona, págs. 83-154.

VERA REBOLLO, J. F., LÓPEZ PALOMEQUE, F., MARCHENA GÓMEZ, M. y ANTÓN CLAVÉ, S. (1997): Análisis territorial del turismo. Ed. Ariel. Barcelona.

VERA, J. F., LÓPEZ, F., MARCHENA, M. J. y ANTÓN, S. (2011) : Análisis territorial del turismo y planificación de destinos turísticos. Tirant lo Blanch, Valencia. 